\title{
Antimicrobial Activity of Thinned Strawbeny Fruits at Different Maturation Stages
}

\author{
Dong Sub Kim ${ }^{1 \dagger}$, Haeyoung $\mathrm{Na}^{2 \dagger}$, Jeong Hwa Song ${ }^{3}$, Yurina Kwack ${ }^{4}$, \\ Sung Kyeom Kim ${ }^{4}$, and Changhoo Chun ${ }^{1,4 *}$ \\ ${ }^{1}$ Department of Plant Science, Seoul National University, Seoul 151-921, Korea \\ ${ }^{2}$ Department of Horticultural Science, Mokpo National University, Muan 534-729, Korea \\ ${ }^{3}$ Division of Horticulture and Education, Korea National Arboretum, Pocheon 487-821, Korea \\ ${ }^{4}$ Research Institute for Agriculture and Life Sciences, Seoul National University, Seoul 151-921, Korea
}

\begin{abstract}
Among the phenolic compounds that is generally present in strawberry fruits, five simple phenolics, three flavonoids, and a stilbene were tested for their antimicrobial activity against seven fungi and one oomycete. trans-Cinnamic acid showed strong antimicrobial activity, and the antimicrobial effect of the simple phenolics decreased with an increase in the number of hydroxyl groups. Phytophthora capsici was the most susceptible to the phenolic compounds tested in this study. trans-Cinnamic acid, $p$-hydroxybenzoic acid, and kaempferol were mainly detected in 'Seolhyang' strawberry fruits, and the total phenolic contents of the fruits decreased during their development. Extracts of the green (1-10\% red color) and red (above 90\% red color) strawberry fruits reduced the mycelial growth and zoospore germination rate of $P$. capsici, and the extract of red strawberry fruit showed strong antimicrobial activity against the zoospore germination of $P$. capsici. These results indicate that strawberry fruits contain antimicrobial phenolic compounds and that strawberry fruit extract can be used as a natural fungistat.
\end{abstract}

Additional key words: Fragaria $\times$ ananassa, hydroxylation, phenolic compounds, Phytophthora capsici

\section{Introduction}

Higher plants synthesize diverse compounds to defend themselves against fungi and bacteria. Antimicrobial substances such as phenolic compounds, terpenoids, and alkaloids are secondary metabolites. Among them the phenolic compounds are especially important as plant defense systems, as are phytoanticipin or phytoalexin (Dixon and Paiva, 1995). The antimicrobial activities of phenolic compounds against bacteria (Herald and Davidson, 1983; Rauha et al., 2000) and fungi (Korukluoglu et al., 2008) have been reported.

Several studies have shown that strawberry (Fragaria $\times$ ananassa Duch.) fruits contain various phenolic compounds (Halbwirth et al., 2006; Kosar et al., 2004). Among these compounds, ellagic acid accounts for $50.9 \%$ of the total phenolic compounds in ripe fruits (Häkkinen et al., 1999). The fruits also contain trans-cinnamic acid, $p$-coumaric acid, caffeic acid, gallic acid, $p$-benzoic acid, kaempferol, morin, myricetin, quercetin, resveratrol, and the phenolic compounds have been attracted attention by higher antimicrobial activity compared to other phenolic compounds. Strawberry extract inhibited the growth of gram-negativebacteria, especially Escherichia coli, and Salmonella enterica ser. Typhimurium, Campylobacter jejuni, and Candida albicans (Nohynek et al., 2006; Puupponen-Pimiä et al., 2001, 2005). In addition, the antimicrobial effect on 1D TLC bioassay plates for ethanol extract of unripe fruit was greater than that of the extract of ripe fruit (Terry et al., 2004).

The previous studies have mainly focused on the phenolic compound contents of marketable strawberries (Aaby et al., 2012; Sultana and Anwar, 2008) or the anti-oxidant, anti-cancer, or anti-proliferative effects of strawberry extract (Meyers et al., 2003; Pincemail et al., 2012; Spada et al., 2008) from edible fruits. Few studies, however, have examined the phenolic compound contents of thinned, immature strawberry fruits or the antimicrobial activity of their extracts. This study was

\footnotetext{
*Corresponding author: changhoo@snu.ac.kr

${ }^{\dagger}$ These authorsare contributed equally to this work.

※ Received 24 October 2012; Revised 23 November 2012; Accepted 23 November 2012. This study was supported by the Regional Joint Agricultural Research Project of RDA (grant no. 20110801030507) in Korea.
} 
conducted to identify the contents and the antimicrobial activity of phenolic compounds which can be used as raw materials for a natural fungist at from thinned strawberry fruits at different maturation stages.

\section{Materials and Methods}

\section{Plant Materials}

Strawberries (Fragaria $\times$ ananassa cv. Seolhyang) were cultivated from October 16, 2006 to July 20, 2007 in a greenhouse in Suwon, Korea (37'16'12’N, 126 59 '20’E, and elevation: $30 \mathrm{~m}$ ). The fruits were thinned on May 26 and June 13,2007 and stored at $-20^{\circ} \mathrm{C}$. Thinned strawberries were classified into four maturation stages according to percentage of red color: $0 \%$ red color, green; $1-10 \%$ red color, white; $10-90 \%$ red color, white-red; and above $90 \%$ red color, red. A chromameter (CR300 Series, Minolta Co., Ltd., Osaka, Japan) was used to determine the chromaticity a* (red-green) of the fruits on the CIE scale. Color readings were performed in one zone from each of five fruits (Ferreyra et al., 2007). The extraction was conducted with the mixture that has in the same proportion of thinned fruits on different days.

\section{In Vitro Antimicrobial Assay of Pure Substances}

In vitro antimicrobial activities against Colletotrichum gloeosporioides, Colletotrichum musae, Colletotrichum falcatum, Cochliobolous miyabeanus, Magnaporthe grisea, Magnaporthe oryzae, Botrytis cinerea, and Phytophthora capsici were determined. Fungi and oomycete were obtained from the Center for Fungal Genetic Resources, Seoul National University, Seoul, Korea and the Rural Development Administration Genebank Information Center, Suwon, Korea, respectively.

The pure substances tested for their antimicrobial activity were trans-cinnamic acid, $p$-coumaric acid, caffeic acid, gallic acid, kaempferol, morin, myricetin, quercetin, trans-resveratrol (Sigma-Aldrich, St. Louis, MO, USA), and $p$-hydroxybenzoic acid (SamchunPure Chemical Co., Pyeongtaek, Korea). Dimethomorph was used as atechnical-grade standard fungicide (BASF Corp., Research Triangle Park, NC, USA).

To estimate inhibitory effects of pure substances on the mycelium growth, 10,50 , and $100 \mathrm{mg}$ of the simple phenolics, the flavonoids, and a stilbene were dissolved in $1 \mathrm{~mL}$ of $100 \%$ methyl alcohol. They were then blended with $100 \mathrm{~mL}$ of a PDA culture solution, and $1 \mathrm{~mL}$ of each mixture was plated in a 24-well tissue culture test plate (i.d.: $16 \mathrm{~mm}$ ). Finally, the concentration of pure substances was adjusted to $0.1,0.5$, and $1.0 \mathrm{~g} \cdot \mathrm{L}^{-1}$, respectively. A piece of the mycelia of the fungi and an oomycete was placed in the middle of each test plate and incubated in a growth chamber (air temperature: $26^{\circ} \mathrm{C}$; humidity: $20 \%$; and photoperiod: $0 \mathrm{~h} \cdot \mathrm{d}^{-1}$ ). After a week, the mycelial diameter was classified into three categories.

\section{Extraction and Hydrolysis}

The phenolic compounds were extracted and hydrolyzed according to the procedure described by Häkkinen et al. (1998). Thinned strawberry fruits (20 g for HPLC analysis, and $200 \mathrm{~g}$ and $400 \mathrm{~g}$ for antimicrobial assay) were homogenized with $1.2 \mathrm{M} \mathrm{HCl}$ in $50 \%(\mathrm{v} / \mathrm{v})$ aqueous methanol and ascorbic acid $(80 \mathrm{mg}$ ). The mixture was sonicated for $2 \mathrm{~min}$, and the remaining air in the bottle was substituted with nitrogen gas. The extract was shaken in a $35^{\circ} \mathrm{C}$ water bath in the dark for $16 \mathrm{~h}$ before it was cooled and filtered. A $15 \mathrm{~mL}$ portion of the filtrate was evaporated using a rotary evaporator at $35^{\circ} \mathrm{C}$. The residue was dissolved in $2 \mathrm{~mL}$ of methanol and filtered through a $0.45 \mu \mathrm{m}$ filter.

\section{HPLC Conditions}

The HPLC procedure in this study was previously described by Häkkinen et al. (1998). A Zorbax ODS C-18 column $[150 \times 4.6 \mathrm{~mm}$, i.d. $5 \mu \mathrm{m}$ (AgilentTechnologies, Waldbronn, Germany)] was used for the analysis. The solvents used were (a) $50 \mathrm{mM}$ ammonium dihydrogen phosphate (pH: 2.6); (b) $0.2 \mathrm{mM}$ ortho-phosphoric acid (pH: 1.5); and (c) 20\% solvent (a) in $80 \%$ acetonitrile. $p$-Hydroxybenzoic acid was detected at $260 \mathrm{~nm}$; gallic acid and trans-cinnamic acid at $280 \mathrm{~nm}$; p-coumaric acid and caffeic acid at $320 \mathrm{~nm}$; and flavonoids at $360 \mathrm{~nm}$.

\section{Antimicrobial Assay of Extract of Thinned Strawberry Fruits}

To estimate the inhibitory effects of fruit extract on the mycelium growth, PDA medium $(100 \mathrm{~mL})$ was made by adding $100 \mu \mathrm{L}$ of methyl alcohol (control) or extract of thinned strawberry fruits. The treatment of $100 \mu \mathrm{L}$ extract from 200 and $400 \mathrm{~g}$ thinned green fruit equals to 24 and $48 \mathrm{mg} \cdot \mathrm{L}^{-1}$ total phenolic compound concentrations, respectively. Likewise, the treatment of $100 \mu \mathrm{L}$ extract from 200 and $400 \mathrm{~g}$ thinned red fruit equals to 15 and $29 \mathrm{mg} \cdot \mathrm{L}^{-1}$ total phenolic compound, respectively. The mixtures were placed into petri dishes. Dimethomorph $(10 \mu \mathrm{L})$, a technical-grade agrochemical fungicide with different modes of action, was used as an internal standard in the $10 \mathrm{~mL}$ PDA culture solution. Mycelia of Phytophthora capsici (6 $\mathrm{mm}$ in diameter) was placed in the middle of each petri dish and incubated in a growth chamber (air temperature, $26^{\circ} \mathrm{C}$; humidity, $20 \%$; photoperiod, $\left.16 \mathrm{~h} \cdot \mathrm{d}^{-1}\right)$. The mycelial diameter was measured with a ruler for six days, and the average of the two measurements was expressed in millimeters.

To estimate the inhibitory effects of fruit extract on the zoospore germination, $\mathrm{V} 8$ juice medium $(100 \mathrm{~mL})$ was made 
by adding $100 \mu \mathrm{L}$ of methyl alcohol (control) or extract of thinned strawberry fruits. The mixtures were placed in petri dishes. Twelve mm of mycelia of Phytophthora capsici was placed in the middle of each petri dish and incubated in a growth chamber (air temperature, $26^{\circ} \mathrm{C}$; humidity, $20 \%$; photoperiod, $\left.16 \mathrm{~h} \cdot \mathrm{d}^{-1}\right)$. After four days, the mycelia were dislodged by softly brushing the colonies with an iron rod. They were dried for two days, after which $20 \mathrm{~mL}$ of distilled water was added, and the dishes were stored at $4^{\circ} \mathrm{C}$ for 90 min. The number of zoospores of Phytophthora capsici was counted using a disposable hemocytometer (Digital Bio, Seoul, Korea), and the concentration was adjusted to $1 \times 10^{4}$ zoospores $\cdot \mathrm{mL}^{-1}$.

\section{Statistical Analysis}

Analysis of variance (ANOVA) was performed, and the means were compared with the least significant difference (LSD) at the 0.05 probability level using SAS 9.1 (SAS Institute Inc., Cary, NC, USA).

\section{Results and Discussion}

In Vitro Antimicrobial Activity of the Pure Substances

Among the five simple phenolics, trans-cinnamic acid,

Table 1. Antimicrobial activity of the five simple phenolics, three flavonoids, and a stilbene against the mycelial growth of seven fungi and one oomycete.

\begin{tabular}{|c|c|c|c|c|c|c|c|c|c|}
\hline & \multirow{2}{*}{$\begin{array}{l}\text { Conc. } \\
\left(\mathrm{g} \cdot \mathrm{L}^{-1}\right)\end{array}$} & \multicolumn{8}{|c|}{ Fungi and oomycete } \\
\hline & & $\begin{array}{l}\text { Colletotrichum } \\
\text { gloeosporioides }\end{array}$ & $\begin{array}{c}\text { Colletotrichum } \\
\text { musae }\end{array}$ & $\begin{array}{c}\text { Colletotrichum } \\
\text { falcatum }\end{array}$ & $\begin{array}{c}\text { Cochliobolous } \\
\text { miyabeanus }\end{array}$ & $\begin{array}{c}\text { Magnaporthe } \\
\text { grisea }\end{array}$ & $\begin{array}{c}\text { Magnaporthe } \\
\text { oryzae }\end{array}$ & $\begin{array}{l}\text { Botrytis } \\
\text { cinerea }\end{array}$ & $\begin{array}{c}\text { Phytophthora } \\
\text { capsici }\end{array}$ \\
\hline Control & 0.0 & ++ & ++ & ++ & ++ & ++ & ++ & ++ & ++ \\
\hline trans- & 0.1 & ++ & ++ & - & ++ & ++ & ++ & ++ & - \\
\hline \multirow{2}{*}{$\begin{array}{l}\text { Cinnamic } \\
\text { acid }\end{array}$} & 0.5 & - & - & - & - & - & - & ++ & - \\
\hline & 1.0 & - & - & - & - & - & - & - & - \\
\hline \multirow{3}{*}{$\begin{array}{l}p \text {-Coumaric } \\
\text { acid }\end{array}$} & 0.1 & ++ & ++ & ++ & ++ & ++ & ++ & ++ & ++ \\
\hline & 0.5 & ++ & + & ++ & ++ & ++ & ++ & ++ & - \\
\hline & 1.0 & - & - & ++ & ++ & ++ & ++ & ++ & - \\
\hline \multirow{3}{*}{$\begin{array}{l}\text { Caffeic } \\
\text { acid }\end{array}$} & 0.1 & ++ & ++ & ++ & ++ & ++ & ++ & ++ & ++ \\
\hline & 0.5 & ++ & ++ & ++ & ++ & ++ & ++ & ++ & ++ \\
\hline & 1.0 & ++ & ++ & ++ & ++ & ++ & ++ & ++ & - \\
\hline \multirow{3}{*}{$\begin{array}{l}p \text {-Hydroxy- } \\
\text { benzoic } \\
\text { acid }\end{array}$} & 0.1 & ++ & ++ & ++ & ++ & ++ & ++ & ++ & ++ \\
\hline & 0.5 & ++ & ++ & ++ & ++ & ++ & ++ & ++ & - \\
\hline & 1.0 & ++ & ++ & ++ & ++ & ++ & ++ & ++ & - \\
\hline \multirow[t]{3}{*}{ Gallic acid } & 0.1 & ++ & ++ & ++ & ++ & ++ & ++ & ++ & ++ \\
\hline & 0.5 & ++ & ++ & ++ & ++ & ++ & ++ & ++ & ++ \\
\hline & 1.0 & ++ & ++ & + & ++ & ++ & + & ++ & ++ \\
\hline \multirow[t]{3}{*}{ Kaempferol } & 0.1 & ++ & ++ & ++ & ++ & ++ & ++ & ++ & ++ \\
\hline & 0.5 & ++ & ++ & ++ & ++ & ++ & ++ & ++ & ++ \\
\hline & 1.0 & ++ & ++ & ++ & ++ & ++ & ++ & ++ & ++ \\
\hline \multirow[t]{3}{*}{ Quercetin } & 0.1 & ++ & ++ & ++ & ++ & ++ & ++ & ++ & ++ \\
\hline & 0.5 & ++ & ++ & ++ & ++ & ++ & ++ & ++ & ++ \\
\hline & 1.0 & ++ & ++ & ++ & ++ & ++ & ++ & ++ & ++ \\
\hline \multirow[t]{3}{*}{ Morin } & 0.1 & ++ & ++ & ++ & ++ & ++ & ++ & ++ & ++ \\
\hline & 0.5 & ++ & ++ & ++ & ++ & ++ & ++ & ++ & ++ \\
\hline & 1.0 & ++ & ++ & ++ & ++ & ++ & ++ & ++ & ++ \\
\hline trans- & 0.1 & ++ & ++ & ++ & ++ & ++ & + & ++ & ++ \\
\hline \multirow[t]{2}{*}{ Resveratrol } & 0.5 & ++ & ++ & ++ & ++ & ++ & + & ++ & ++ \\
\hline & 1.0 & ++ & ++ & ++ & ++ & ++ & + & ++ & ++ \\
\hline
\end{tabular}

Strong antimicrobial activity, mycelia filled a cell $(16 \mathrm{~mm})$.

${ }^{+}$Moderate antimicrobial activity, mycelia grew by $1-15 \mathrm{~mm}$.

${ }^{++}$No antimicrobial activity, mycelia did not grow $(0 \mathrm{~mm})$. 
which has no hydroxyl group on the aromatic ring, strongly inhibited the mycelial growth of all tested microorganisms (Table 1). More than $0.1 \mathrm{~g} \cdot \mathrm{L}^{-1}$ of trans-cinnamic acid inhibited the mycelial growth of Colletotrichum falcatum and Phytophthora capsici, more than $0.5 \mathrm{~g} \cdot \mathrm{L}^{-1}$ inhibited the mycelial growth of Colletotrichum gloeosporioides, Colletotrichum musae, Cochliobolous miyabeanus, Magnaporthe grisea, and Magnaporthe oryzae, and $1.0 \mathrm{~g} \cdot \mathrm{L}^{-1}$ inhibitedthe mycelial growth of Botrytis cinerea. More than $0.5 \mathrm{~g} \cdot \mathrm{L}^{-1}$ of $p$-coumaric acid, which has a hydroxyl group on the aromatic ring, inhibited the mycelial growth of Colletotrichum musae and Phytophthora capsici and $1.0 \mathrm{~g} \cdot \mathrm{L}^{-1}$ inhibited the mycelial growth of Colletotrichum gloeosporioides. More than $0.5 \mathrm{~g} \cdot \mathrm{L}^{-1}$ of $p$-hydroxybenzoic acid, which has a hydroxyl group on the aromatic ring, inhibited the mycelial growth of Phytophthora capsici. Also, the mycelial growth of Phytophthora capsici was inhibited by $1.0 \mathrm{~g} \cdot \mathrm{L}^{-1}$ of caffeic acid that has two hydroxyl groups on the aramatic ring. The mycelial growth of Colletotrichum falcatum and Magnaporthe oryzae moderately was inhibited by $1.0 \mathrm{~g} \cdot \mathrm{L}^{-1}$ of gallic acid that has three hydroxyl groups on the aromatic ring. Consequently, four simple phenolics, excluding gallic acid, inhibited the mycelial growth of Phytophthora capsici, but their antimicrobial activity against Phytophthora capsici decreased with an increase in the number of hydroxyl groups on the aromatic ring. Kim et al. (2004) reported that the order of highest to lowest antifungal activity against Aspergillus flavus was cinnamic acid $>p$-coumaric acid $>$ caffeic acid. Ramos-Nino et al. (1996) demonstrated that the antimicrobial activity of trans-cinnamic acid against Listeria monocytogenes decreased afterthe hydroxylation of its aromatic ring.

Many researchers have studied the antiviral and antimicrobial

Table 2. Changes in external color of the thinned 'Seolhyang' strawberry fruits classified into four maturation stages at harvest.

\begin{tabular}{lcr}
\hline \hline Maturation stages & Percentage of red color $(\%)$ & \multicolumn{1}{c}{$\mathrm{a}^{*}$} \\
\hline Green & 0 & $-5.52 \pm 0.70$ \\
White & $1-10$ & $3.47 \pm 1.24$ \\
White-red & $10-90$ & $20.46 \pm 0.86$ \\
Red & $>90$ & $33.22 \pm 0.69$ \\
\hline
\end{tabular}

activities of flavonoids. For instance, flavonoids were found to inhibit the potato virus $\mathrm{X}$ infectivity of Chenopodium quinoa (French and Towers, 1992), the growth of Staphylococcus aureus, Staphylococcus epidermids, and Micrococcus luteus (Rauha et al., 2000), and the mycelial growth of Phytophthora sojae (Rivera-Vargas et al., 1993). However, flavonoids did not show any antimicrobial effects in this study.

The antimicrobial effect of resveratrol has been confirmed in some studies (Bavaresco et al., 2003; Jiménez et al., 2005; and Ureňa, 2003). In this study, more than $0.1 \mathrm{~g} \cdot \mathrm{L}^{-1}$ of trans-r esveratrol moderately inhibited the mycelial growth of $M$. oryzae.

\section{Phenolic Compound Contents of Strawberry Fruits}

Changes in $\mathrm{a}^{*}$ values show that the strawberry color changed from green to red as maturity increased (Ménager et al., 2004). The $a^{*}$ values of thinned 'Seolhyang' fruits classified according to percentage of red color increased with increasing fruit development stage (Table 2). Phenolic compounds such as trans-cinnamic acid, $p$-hydroxybenzoic acid, and kaempferol, were mainly detected in thinned strawberry fruits (Table 3), but $p$-coumaric acid, caffeic acid, gallic acid, morin, myricetin, and quercetin were not detected. Sultana and Anwar (2008) reported the presence of kaempferol and myricetin in strawberry fruits, and Häkkinen and Törrönen (2000) detected kaempferol, quercetin, and $p$-coumaric acid in fruits of nine strawberry cultivars. These differences in findings might have been due to the differences in the cultivars, cropping systems, field environment, orextraction methods of the analyzed strawberries. trans-Cinnamic acid contents of the green, white, white-red, and red strawberry fruits were $4.97 \pm 1.45,4.68 \pm 1.10$, $3.17 \pm 1.09$, and $2.91 \pm 0.45 \mu \mathrm{g} \cdot \mathrm{g}^{-1} \mathrm{FW}$, respectively. Ehala et al. (2005) reported that the trans-cinnamic acid content of red strawberry fruits was $10.81 \pm 1.36 \mu \mathrm{g} \cdot \mathrm{g}^{-1} \mathrm{FW} . p$ Hydroxybenzoic acid contents of the green, white, white-red, and red strawberry fruits were $1.90 \pm 0.68,2.36 \pm 1.49$, $2.38 \pm 1.32$, and $1.42 \pm 1.18 \mu \mathrm{g} \cdot \mathrm{g}^{-1} \mathrm{FW}$, respectively. Stöhr and Herrmann (1975) found that the $p$-hydroxybenzoic acid content of red strawberry fruits was $10-15 \mu \mathrm{g} \cdot \mathrm{g}^{-1} \mathrm{FW}$. Kaempferol contents of green, white, white-red, and red strawberry fruits were $5.16 \pm 1.15,4.54 \pm 1.23,4.96 \pm 0.80$,

Table 3. Phenolic compound contents $\left(\mu \mathrm{g} \cdot \mathrm{g}^{-1} \mathrm{FW}\right)$ of the thinned 'Seolhyang' strawberry fruits cultivated in greenhouse at four maturation stages.

\begin{tabular}{lcccc}
\hline \hline Maturation stages & trans-Cinnamic acid & $p$-Hydroxy benzoic acid & Kaempferol & Total phenolic compound \\
\hline Green & $4.97 \pm 1.45$ & $1.90 \pm 0.68$ & $5.16 \pm 1.15$ & $12.02 \pm 1.06$ \\
White & $4.68 \pm 1.10$ & $2.36 \pm 1.49$ & $4.54 \pm 1.23$ & $11.59 \pm 0.75$ \\
White-red & $3.17 \pm 1.09$ & $2.38 \pm 1.32$ & $4.96 \pm 0.80$ & $10.51 \pm 0.76$ \\
Red & $2.91 \pm 0.45$ & $1.42 \pm 1.18$ & $2.94 \pm 1.38$ & $7.26 \pm 0.50$ \\
\hline
\end{tabular}


and $2.94 \pm 1.38 \mu \mathrm{g} \cdot \mathrm{g}^{-1} \mathrm{FW}$, respectively. Häkkinen and Törrönen (2000) found that the kaempferol content of red strawberry fruits was $2.0-9.0 \mu \mathrm{g} \cdot \mathrm{g}^{-1} \mathrm{FW}$. The total phenolic contents of green, white, white-red, and red strawberry fruits was $12.02 \pm 1.06,11.59 \pm 0.75,10.51 \pm 0.76$, and 7.26 $\pm 0.50 \mu \mathrm{g} \cdot \mathrm{g}^{-1} \mathrm{FW}$, respectively. Compared with the previous studies, the thinned 'Seolhyang' strawberry fruits had low phenolic contents. Maas et al. (1991) reported that the contents of phenolic compounds in the tissues of strawberry cultivars differed widely. The phenolic content of 'Seolhyang' strawberry fruits tended to decrease during fruit development in this study, too. Ferreyra et al. (2007) and Montero et al. (1996) showed that total phenolic content decreased during strawberry fruit development. Halbwirth et al. (2006) reported that the concentration of simple phenolics in strawberry fruits decreased continuously and that flavonol contents increased rapidly during fruit development.

\section{Antimicrobial Activity of the Extract of the Thinned Strawberry Fruit}

The extracts of thinned strawberry fruits inhibited mycelial growth, and the antimicrobial effect increased with anincrease in the amount of strawberry fruit used (Fig. 1). The 200 $\mathrm{g}$ extract of the green (total phenolic compound $24 \mathrm{mg} \cdot \mathrm{L}^{-1}$ ) and red (total phenolic compound $15 \mathrm{mg} \cdot \mathrm{L}^{-1}$ ) strawberry fruits on day 5 had reduced mycelial growth by 20.93 and $24.24 \%$, respectively. When the amount of strawberry fruit used was doubled, mycelial growth decreased by 39.48 and $42.22 \%$, respectively.

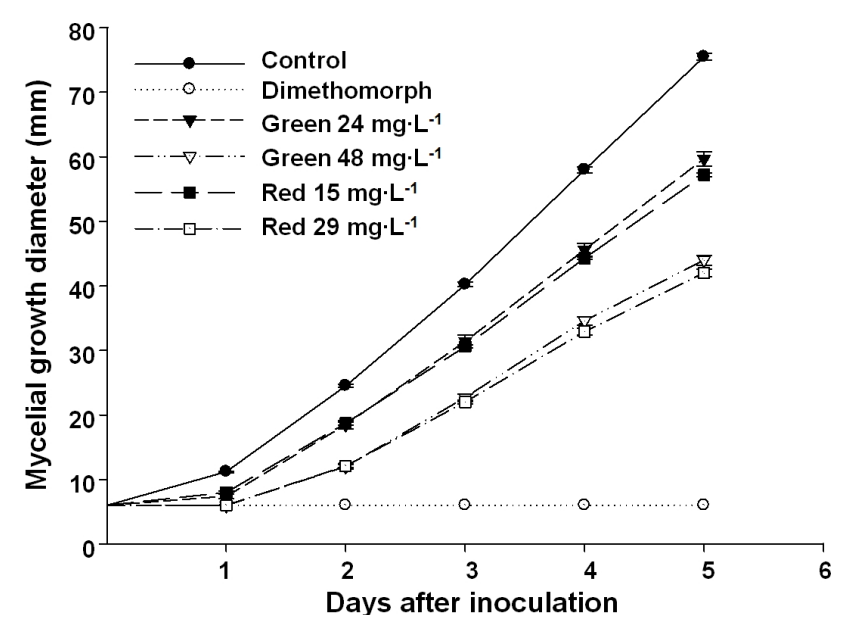

Fig. 1. Mycelial growth curve of Phytophthora capsici inextracts of the thinned strawberry fruit cultivated in greenhouse. In thinned green fruit, 24 and $48 \mathrm{mg} \cdot \mathrm{L}^{-1}$ indicate the total phenolic compound concentrations in the $100 \mu \mathrm{L}$ extract from 200 and $400 \mathrm{~g}$ fruit, respectively. In thinned red fruit, 15 and $29 \mathrm{mg} \cdot \mathrm{L}^{-1}$ indicate the total phenolic compound concentrations in the $100 \mu \mathrm{L}$ extract from 200 and $400 \mathrm{~g}$ fruit, respectively. The vertical bars represent the standard errors of the means.
The zoospore germination rate was inhibited by strawberry fruit extract, and the antimicrobial effect of red strawberry fruit was greater than that of green strawberry fruit (Fig. 2). The $200 \mathrm{~g}$ extracts of green and red strawberry fruits inhibited zoospore germination by about 65.52 and $55.17 \%$, respectively, and the $400 \mathrm{~g}$ extracts of green and red strawberry fruits inhibited zoospore germination by about 80.51 and $94.05 \%$, respectively, compared to the control. Stephan et al. (2005) reported that zoospore of Phytophthora infestans was susceptible to the extract of Rheum rhabarbarum L. and Solidago Canadensis L. although no inhibitory effects on mycelial growth were observed. This indicates that the reproductive organs of Phytophthora spp. are more sensitive than the vegetative organs.

The total phenolic content of green strawberry fruits was greater than that of red strawberry fruits, but the extract of red strawberry fruits showed the higher antimicrobial effect. This result might be caused by the smaller ratio of kaempferol showing no antimicrobial activity out of total phenolic compound in mature red fruits $(40.5 \%)$ comparing to that in immature green fruits (42.9\%). Rivera-Vargas et al. (1993) reported that antimicrobial effects of certain phenolic compounds having antimicrobial activity or their mixture decreased when they were mixed with other non-active phenolic compounds.

We found that the extracts of thinned strawberry fruits contained antimicrobial phenolic compounds such as transcinnamic acid and $p$-hydroxybenzoic acid, even though their contents were smaller than those in mature red fruits. It suggests that the thinned fruits during developmental stages

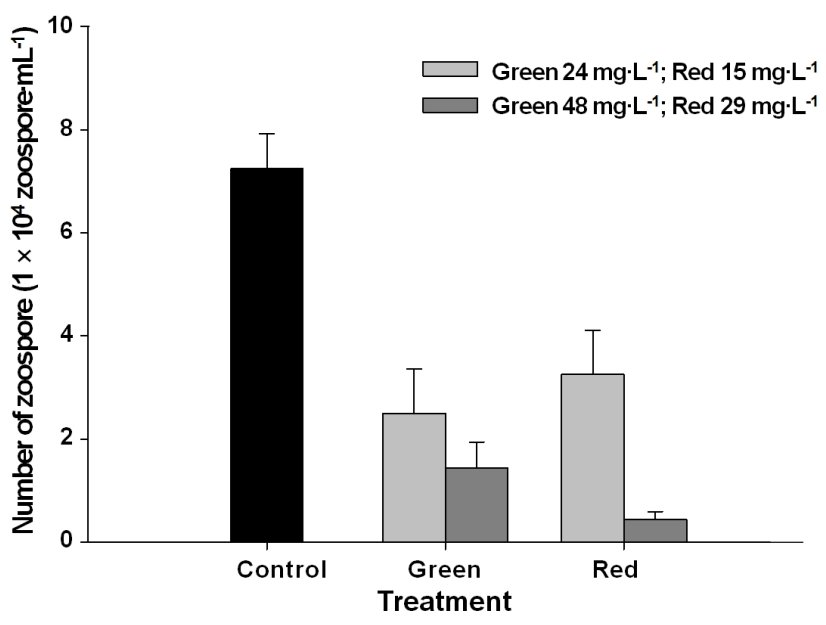

Fig. 2. Inhibitory effect of extracts of the thinned strawberry fruit cultivated in greenhouse on zoospore germination of Phytophthora capsici. In thinned green fruit, 24 and $48 \mathrm{mg} \cdot \mathrm{L}^{-1}$ indicate the total phenolic compound concentrations in the $100 \mu \mathrm{L}$ extract from 200 and $400 \mathrm{~g}$ fruit, respectively. In thinned red fruit, 15 and $29 \mathrm{mg} \cdot \mathrm{L}^{-1}$ indicate the total phenolic compound concentrations in the $100 \mu \mathrm{L}$ extract from 200 and $400 \mathrm{~g}$ fruit, respectively. The vertical bars represent the standard errors of the means. 
and the non-marketable fruits at the end of strawberry cultivation can be used as a natural fungistat, while they have conventionally been threw away with debris of strawberry plants. Enhancement of phenolic compound level by applying stress treatments such as UV-light illumination, water deficiency, and etc. (Treutter, 2006) and analysis of phenolic compounds in nonedible parts of strawberry plants and the irutilization might be needed to improve the production efficiency of natural fungistats utilizing the discarded plants parts of strawberry.

\section{Literature Cited}

Aaby, K., S. Mazur, A. Nes, and G. Skrede. 2012. Phenolic compounds in strawberry (Fragaria $\times$ ananassa Duch.) fruits: Composition in 27 cultivars and changes during ripening. Food Chem. 132:86-97.

Bavaresco, L., S. Vezzulli, P. Battilani, P. Giorni, A. Pietri, and T. Bertuzzi. 2003. Effect of ochratoxin A-producing Aspergilli on stilbenic phytoalex in synthesis in grapes. J. Agric. Food Chem. 51:6151-6157.

Dixon, R.A. and N.L. Paiva. 1995. Stress-induced phenylpropanoid metabolism. Plant Cell 7:1085-1097.

Ehala, S., M. Vaher, and M. Kaljurand. 2005. Characterization of phenolic profiles of northern European berries by capillary electrophoresis and determination of their antioxidant activity. J. Agric. Food Chem. 53:6484-6490.

Ferreyra, R.M., S.Z. Viňa, A. Mugridge, and A.R. Chaves. 2007. Growth and ripening season effects on antioxidant capacity of strawberry cultivar Selva. Sci. Hort. 112:27-32.

French, C.J. and G.H.N. Towers. 1992. Inhibition of infectivity of potato virus X by flavonoids. Phytochemistry 31:3017-3020.

Häkkinen, S.H. and A.R. Törrönen. 2000. Content of flavonols and selected phenolic acids in strawberries and Vaccinium species: Influence of cultivar, cultivation site and technique. Food Res. Intl. 33:517-524.

Häkkinen, S.H., I.M. Heinonen, S.O. Kärenlampi, H.M. Mykkänen, J. Ruuskanen, and A.R. Törrönen. 1999. Screening of selected favonoids and phenolic acids in 19 berries. Food Res. Intl. $32: 345-353$.

Häkkinen, S.H., S.O. Kärenlampi, I.M. Heinonen, H.M. Mykkänen, and A.R. Törrönen. 1998. HPLC method for screening of flavonoids and phenolic acids in berries. J. Sci. Food Agric. 77:543-551

Halbwirth, H., I. Puhl, U. Haas, K. Jezik, D. Treutter, and K. Stich. 2006. Two-phase flavonoid formation in developing strawberry (Fragaria $\times$ ananassa) fruit. J. Agric. Food Chem. 54:1479-1485.

Herald, P.J. and P.M. Davidson. 1983. Antibacterial activity of selected hydroxycinnamic acids. J. Food Sci. 48:1378-1379.

Jiménez, J.B., J.M. Orea, C. Montero, Á.G. Ureňa, E. Navas, K. Slowing, M.P. Gómez-Serranillos, E. Carretero, and D.D. Martinis. 2005. Resveratrol treatment controls microbial flora, prolongs shelf life, and preserves nutritional quality of fruits. J. Agric. Food Chem. 53:1526-1530.

Kim, J.H., B.C. Campbell, N.E. Mahoney, K.L. Chan, and R.J.
Molyneux. 2004. Identification of phenolics for control of Aspergillus flavus using Saccharomyces cerevisiae in a model target-gene bioassay. J. Agric. Food Chem. 52:7814-7821.

Kosar, M., E. Kafkas, S. Paydas, and K.H.C. Baser. 2004. Phenolic composition of strawberry genotypes at different maturation stages. J. Agric. Food Chem. 52:1586-1589.

Korukluoglu, M., Y. Sahan, and A. Yigit. 2008. Antifungal properties of olive leaf extracts and their phenolic compounds. J. Food Safety 28:76-87.

Maas, J.L., S.Y. Wang, and G.J. Galletta. 1991. Evaluation of strawberry cultivars for ellagic acid content. HortScience 26:66-68

Ménager, I., M. Jost, and C. Aubert. 2004. Changes in physicochemical characteristics and volatile constituents of strawberry (cv. Cigaline) during maturation. J. Agric. Food Chem. 52: 1248-1254.

Meyers, K.J., C.B. Watkins, M.P. Pritts, and R.H. Liu. 2003. Antioxidant and antiproliferative activities of strawberries. J. Agric. Food Chem. 51:6887-6892.

Montero, T.M., E.M. Mollá, R.M. Esteban, and F.J. López-Andréu. 1996. Quality attributes of strawberry during ripening. Sci. Hort. 65:239-250.

Nohynek, L.J., H.L. Alakomi, M.P. Kähkönen, M. Heinonen, I.M. Helander, K.M. Oksman-Caldentey, and R.H. PuupponenPimiä. 2006. Berry phenolics - Antimicrobial properties and mechanisms of action against severe human pathogens. Nutr. Cancer 54:18-32.

Pincemail, J., C. Kevers, J. Tabart, J.O. Defraigne, and J. Dommes. 2012. Time influence phenolic and ascorbic acid contents and antioxidant capacity of strawberry (Fragaria $\times$ ananassa). J. Food Sci. 77:205-210.

Puupponen-Pimiä, R., L. Nohynek, C. Meier, M. Kähkönen, M. Heinonen, A. Hopia, and K.M. Oksman-Caldentey. 2001. Antimicrobial properties of phenolic compounds from berries. J. Appl. Microbiol. 90:494-507.

Puupponen-Pimiä, R., L. Nohynek, S. Hartmann-Schmidlin, M. Kähkönen, M. Heinonen, K. Määttä-Riihinen, and K.M. Oksman-Caldentey. 2005. Berry phenolics selectively inhibit the growth of intestinalpathogens. J. Appl. Microbiol. 98: 991-1000.

Ramos-Nino, M.E., M.N. Clifford, and M.R. Adams. 1996. Quantitative structure activity relationship for the effect of benzoic acids, cinnamic acids and benzaldehydes on Listeria monocytogenes. J. Appl. Bacteriol. 80:303-310.

Rauha, J.P., S. Remes, M. Heinonen, A. Hopia, M. Kähkönen, T. Kujala, K. Pihlaja, H. Vuorela, and P. Vuorela. 2000. Antimicrobial effects of Finnish plant extracts containing flavonoids and other phenolic compounds. Intl. J. Food Microbial. 56:3-12.

Rivera-Vargas, L.I., A.F. Schmitthenner, and T.L. Graham. 1993. Soybean flavonoid effects on and metabolism by Phytophthora sojae. Phytochemistry 32:851-857.

Spada, P.D.S., G.G.N. de Souza, G.V. Bortolini, J.A.P. Henriques, and M. Salvador. 2008. Antioxidant, mutagenic, and antimutagenic activity of frozen fruits. J. Med. Food 11:144-151.

Stephan, D., A. Schmitt, S.M. Carvalho, B. Seddon, and E. Koch. 2005. Evaluation of biocontrol preparations and plant 
extracts for the control of Phytophthora infestans on potato leaves. Eur. J. Plant Pathol. 112:235-246.

Stöhr, H. and K. Herrmann. 1975. The phenolics of fruits. V. The phenolics of strawberries and their changes during development and ripeness of the fruits. Z. Jebensm Unters-Forsch. 159: 341-348.

Sultana, B. and F. Anwar. 2008. Flavonols (kaempferol, quercetin, myricetin) contents of selected fruits, vegetables and medicinal plants. Food Chem. 108:879-884.
Terry, L.A., D.C. Joyce, N.K.B. Adikaram, and B.P.S. Khambay. 2004. Preformed antimicrobial compounds in strawberry fruit and flower tissues. Postharvest Biol. Technol. 31:201-212.

Treutter, D. 2006. Significance of flavonoids in plant resistance: A review. Environ. Chem. Lett. 4:147-157.

Ureňa, Á.G., J.M. Orea, C. Montero, and J.B. Jiménez. 2003. Improving postharvest resistance in fruits by external application of trans-resveratrol. J. Agric. Food Chem. 51:82-89. 